\title{
Energy and Exergy Analysis Study of Heat Exchanger in a Refrigeration System with Different Lengths of Capillary Tube
}

\author{
Thamer Khalif Salem ${ }^{1, *}$, Saad Sami Farhan², Israa Sami Farhan ${ }^{3}$ \\ 1,2,3 Engineering Faculty, Mechanical Department, Tikrit University, Tikrit, Iraq \\ E-mail: ${ }^{1}$ thamer.salem@ ozu.edu.tr; ${ }^{1}$ thamersa1974@tu.edu.iq; ${ }^{2}$ saadsami@tu.edu.iq; ${ }^{3}$ israa.s.farhan@
}

Received 27 June 2020, Revised 9 August 2020, Accepted 8 November 2020

\begin{abstract}
An experimental study was conducted to demonstrate the effect of a capillary tube length on the refrigeration system performance by adding heat exchanger. The heat exchanger was designed by laterally welding $70 \mathrm{~cm}$ of capillary tube with the suction line. Different lengths of the capillary tubes, i.e. 160, 175, and 190cm, were studied; besides different refrigerant flow rates and condenser air fan velocities for both cases of adiabatic and nonadiabatic capillary tube. The experimental results showed an increase in the system performance by $17.96 \%$ with a decrease in the nonadiabatic capillary tube length from 190 to $160 \mathrm{~cm}$ at mass flow rate of $17.3 \mathrm{~kg} / \mathrm{hr}$ and air velocity of $3 \mathrm{~m} / \mathrm{s}$. In addition, the increase in the air-speed has led to a COP increment by $17.47 \%$ at mass flow rate of $18.9 \mathrm{~kg} / \mathrm{hr}$ and capillary tube length of $190 \mathrm{~cm}$. Finally, at the capillary tube length of $190 \mathrm{~cm}$ and refrigerant mass flow rate of $2.4 \mathrm{~g} / \mathrm{s}$, the maximum enhancement of the refrigeration system performance and exergy efficiency by $6.7 \%$ and $35 \%$, respectively, was achieved for air speed of $1 \mathrm{~m} / \mathrm{s}$ and $3 \mathrm{~m} / \mathrm{s}$, compared to the reference case of the adiabatic capillary tubes.
\end{abstract}

Keywords: Capillary tube length; Suction line; Exergy; Heat exchanger; R134a.

\section{Introduction}

Capillary tube is an expansion device that is used to reduce the pressure and temperature of working fluid from high pressure in the condenser to low pressure in the evaporator due to the friction factor and acceleration of a refrigerant. The manufacturing of a capillary tube is very simple with different dimensions in diameter, length, coils numbers and diameter [1][2][3]. The improvement in the performance of a refrigeration system is achieved by adding a heat exchanger (capillary tube - suction line). Adding the heat exchanger grants superheating and subcooling processes at the exits of the condenser and evaporator, respectively. The suction linecapillary tube (SL-CT) works as a heat exchanger, where the saturated cold vapor at the exit of the evaporator cools the saturated hot liquid coming from the condenser. The advantage of the superheated process is attained by reducing the forming of liquid droplets inside the superheated steam before entering the compressor. While in the subcooling process, the improvement is realized by preventing the generation of bubbles that may obstruct the flow of liquid through the expansion device [4].

Kuehl and Goldsshmidt [5] conducted an experimental study on capillary tubes of various diameters $(1.07-1.63 \mathrm{~mm})$ and different lengths in a compression refrigeration system operated by (R22). The experimental results showed that the rate of obstruction of the capillary tube increases by $5 \%$ in the case of a capillary tube coil compared to a straight capillary tube. Two correlations were proposed to prove the experimental results. The first one illustrated the relationship between the internal pressure and the refrigerant mass flow rate in the capillary tube. The second correlation was utilized to calculate the coefficient of friction for each diameter of the capillary tubes at different Reynolds numbers. (Garcia, 2007) [6], studied the thermal behavior of a refrigerant within the heat exchange area (capillary tube - suction line) by developing a numerical simulation model of the refrigerant flow. The numerical results were validated by comparing a wide range of experimental results for other publications, which includes the mass flow rate of the refrigerant, the temperature out of the suction line and the temperature along the heat exchange area of the capillary tube and suction line types (concentric and lateral). The results showed the refrigerant flow inside non-adiabatic capillary tubes have more resistance than the adiabatic one because of the refrigerant re-condensation inside the heat exchange area. A numerical study investigated by S. Park et al. [7] to show the effect of adding a heat exchanger (capillary tube - suction line) on the performance of refrigeration cycle. The study was based on mass and energy conservation equations and homogeneous two-phase flow. The simulation results were obtained by changing the length and location of the welded area, between the capillary tube and suction line, to demonstrate the main parameter that affects the system efficiency. An experimental study was conducted by Thamir et al.[8] to determine the effect of capillary tube lengths $(80,100$ and $120 \mathrm{~mm})$ on the refrigeration system performance with using refrigerant (R134a). The experimental results showed the coefficient of performance decreases by $38.14 \%$ and $6.65 \%$ as increasing the mass flow rate and capillary tube lengths respectively. Mohd. K. et al. [9] experimentally investigated the effect of capillary tube diameter, length, and the coil pitch on the mass flow rate of the refrigerant R134a through a spiral capillary line with lateral suction line. The experimental results were validated with the current empirical correlations. An acceptable convergence was found with the largest error percentage of 7\%. Christian [10], presented an algebraic model of heat exchanger (capillary tube - suction line) in a refrigeration device with utilizing two refrigerants R134a and R600a. The comparison results between the algebraic 
model and experimental data showed a good convergence with the value of square root higher than $90 \%$. Several numerical models have been presented by Lyun - Su Kim, et al. [11], and compared with some empirical correlations of the capillary tube and suction line region in a refrigeration system. The numerical results showed that the friction factor has a significant effect on the system performance. Suhaila [12], experimentally investigated the performance of refrigeration system with using two different working fluids, $\mathrm{R} 12$ and R134a. The experimental tests were performed to determine the heat loss from the condenser, the system performance, and the heat transfer coefficient for each refrigerant. The obtained heat transfer coefficients were compared with the correlation equation of Shah [13]. Maximum variation ranged from $5 \%$ to $12 \%$. The exergy analysis had been studied by Ahamed [14] in a compression refrigeration system by utilizing various refrigerants; i.e. R134a, R600a, R407a, and R410a. The results showed that R134a gave the best performance compared to the other refrigerants. In addition, most studies in the refrigeration system showed that the largest losses in exergy occurred through the compressor. Debasish and Ji [15] developed an experimental model based on obtained results from reliable mechanistic model. An empirical model was verified with the experimental results in the literature by using refrigerants (R134a and R600a) [16][17]. A good agreement was found. (Ji H. J. et al.,2012) [18], presented a numerical study to investigate the performance of a refrigeration cycle with a heat exchanger (capillary tube - suction line). The numerical results showed there are two-parameters, i.e. the location and length of the heat exchanger, affect the system performance and cooling capacity. An analytical exergy calculation had been investigated for the conventional refrigeration system using a heat exchanger with various refrigerants R1234yf, R1234ze and R-134a by Naushad et al. [19]. A theoretical model had been improved to determine several parameters such as Coefficient of performance and exergetic efficiency for all refrigerants, while the condenser temperature was kept constant $40{ }^{\circ} \mathrm{C}$, and the evaporator temperature was ranged from $-50{ }^{\circ} \mathrm{C}$ to $0{ }^{\circ} \mathrm{C}$. The theoretical results of the system performance showed that the refrigerants R1234yf and R1234ze are a good substitute with R134a. An analytical study had been presented by Mohan [20] to show the effect of refrigerants, R12 and R134a, on the refrigeration system performance. In addition, the analytical study was based on exergy and energy analysis to investigate the impact of subcooling and evaporator temperatures on the system performance. A mathematical model was developed by Deshmukh and Mudaiya [21], which depends on the conservation of mass, momentum, and energy equations for flow in a heat exchanger (capillary tube-lateral suction line). The physical model was applied as one-dimensional geometry and two-phase flow in the heat exchanger. The numerical results showed a significant effect of the friction coefficient on the pressure drop inside the heat exchanger tubes. Capillary tube diameter, length, and coil pitch were experimentally investigated by Niraj and Avinash [22] to study their effects on the refrigerant flow rate and the system performance. A numerical study was investigated by Matheus et al. [23] of a heat exchanger (capillary tube suction line) in a refrigeration system, which is based on the data from other publications [24][10]. The numerical results illustrated a good agreement in (mass flow rate, critical pressure, exit temperature for the suction line) compared to other results [25][26][16]. Ahmed and Ali [27] presented a theoretical and experimental study on the refrigeration system. In the experimental part, many parameters were studied to show the effect of the amount of air passing on the evaporator and condenser and the voltages supplied to the compressor on the system performance. The experimental results showed that when reducing the amount of air passing on the condenser by $35.8 \%$, the freezing capacity and performance coefficient decreased by $1.6 \%$ and $7.1 \%$, respectively. In addition, a $23 \%$ reduction in the voltage supplied to the compressor reduced the freezing capacity and performance coefficient by $7.7 \%$ and $5.7 \%$, respectively. The theoretical study was prepared by developing a mathematical model (Matlab code) to calculate the performance of the system under the influence of changing the ambient temperature. Energy and exergy analysis of a refrigerator using refrigerant (R134a) studied by Loauy [28]. Nine types of condensers were used during the experimental study according to thermal conductance and internal surface area. In exergy analysis, the result demonstrated that the refrigerator design depends on its thermal conductance rather than its internal surface area. An experimental study of the flow in a heat exchanger (capillary tube - suction line) using refrigerant (R600a) was investigated by Santhosh and Ravi [29]. The experimental results illustrated that the mass flow rate of the refrigerant is reduced by (3-12\%) compared to the adiabatic capillary tube. The experimental results were validated with other correlations [30] using R600a. A good convergence was achieved with maximum variations of $\pm 20 \%$. Issam and Muayad [31], conducted an experimental study of microchannel condensers compared conventional condenser in automotive refrigeration system using R134a. The experimental tests were done at different ranges of ambient temperature from $40{ }^{\circ} \mathrm{C}$ to $65{ }^{\circ} \mathrm{C}$ at a constant automotive internal temperature of $23{ }^{\circ} \mathrm{C}$ and a cooling load of $2200 \mathrm{~W}$. The results showed for the microchannel condenser that the system performance and heat transfer coefficient are higher than a conventional condenser. The main purpose of this study is to find the best possible procedures for improving the system performance. In the present work, energy and exergy calculations have been carried out in order to elucidate the effect of adiabatic and nonadiabatic capillary tubes on the refrigeration system performance and exergy efficiency. The experimental study included different operating parameters such as capillary tube length $(160,175,190 \mathrm{~cm})$, refrigerant flow rate $(0.175$ to $0.3 \mathrm{~L} / \mathrm{min}$ ), and the condenser air fan velocity ( 1 and 3 $\mathrm{m} / \mathrm{s})$. The novelty of this research is attained by testing the lateral suction line heat exchanger at different lengths of the capillary tubes that influence on the system performance and exergy efficiency, while the contact region length between the capillary tube and suction line is kept constant $70 \mathrm{~cm}$.

\section{Experimental Method and Calculations}

The major components of the refrigeration cycle are the reciprocating compressor $1 / 4 \mathrm{hp}$, finned-tube type of condenser and evaporator, which its average heating capacity is $0.95 \mathrm{~kJ} / \mathrm{s}$; and the last part is a straight capillary copper tube with different lengths. An evaporator type finned tube, as shown in Figure 1, consists of an air-fan that passes the air through the fins to enhance the heat transfer rate by forced convection. Accordingly, the heat transfer mechanism in the evaporator was experimented for different air speeds $(1 \mathrm{~m} / \mathrm{s}$ and $3 \mathrm{~m} / \mathrm{s})$. The specifications of the evaporator are 
shown inTable 1. In addition, the experimental tests were applied with adiabatic and nonadiabatic capillary tubes at similar inner diameter $3 \mathrm{~mm}$, with different lengths (160, 175 and $190 \mathrm{~cm}$ ). The tubes length was measured by utilizing pin gauge set with accuracy of $\pm 0.0015 \mathrm{~mm}$. Then, the capillary tubes and the suction line were welded (heat exchanger suction line type lateral) with a contact area length of $70 \mathrm{~cm}$, whereas the diameter of the suction line is $9.5 \mathrm{~mm}$ that is demonstrated in Figure 2 (A and B). A rotameter device type (CRYOTEK T316BL) has been used to measure the volumetric flow rate of refrigerant (R134a), with maximum flowrate of $0.35 \mathrm{Liter} / \mathrm{minute}$. The rotameter tool was placed between the condenser and capillary tube to control the refrigerant flow rates within the refrigeration rig. T-type of thermocouples were connected to the thermometer model (MTR6), with an excellent temperature range between $-5^{\circ} \mathrm{C}$ to $150^{\circ} \mathrm{C}$ and $\pm 0.1^{\circ} \mathrm{C}$ accuracy. Next, the temperatures were recorded at the entrance and exit locations for all parts of the refrigeration system. Especially, the variation in temperatures along the heat exchanger (the capillary tubesuction line) was solved by utilizing many thermocouples to avoid any flow resistance during the expansion process. High and low-pressure gages were used to measure the pressure at condenser exit and evaporator inlet, respectively. The maximum working ranges of high-pressure and low-pressure gage were 35 bar and 15 bar, respectively, with accuracy of \pm 0.03 bar. The experimental analyses have been achieved using EES program. The schematic diagram of the experimental calculations is explained in Figure 3.

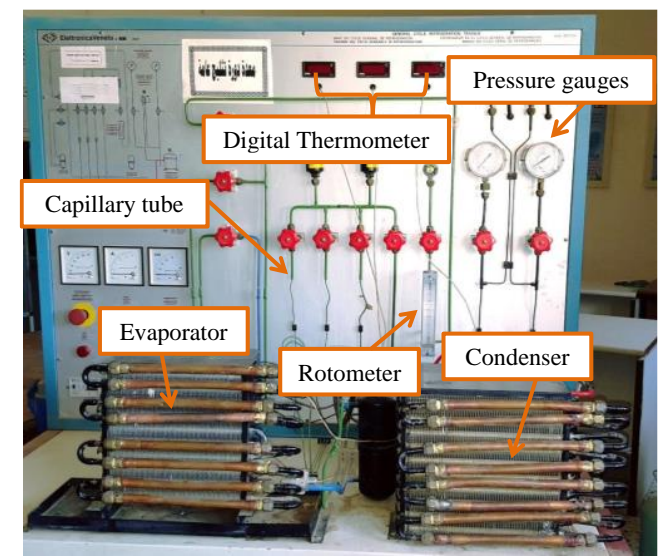

Figure 1. Compression refrigeration rig.

Table 1. the specification and dimensions of all refrigeration system components

\begin{tabular}{|c|c|c|c|c|}
\hline Specification & Condenser & $\begin{array}{c}\text { Capillary } \\
\text { tube }\end{array}$ & $\begin{array}{c}\text { Suction } \\
\text { line }\end{array}$ & Evaporator \\
\hline $\begin{array}{l}\text { Internal tube } \\
\text { diameter }\left(\mathrm{d}_{\mathrm{i}}\right)\end{array}$ & $6.5 \mathrm{~mm}$ & $3 \mathrm{~mm}$ & 9.5 & $6.5 \mathrm{~mm}$ \\
\hline $\begin{array}{l}\text { External tube } \\
\text { diameter }\left(\mathrm{d}_{\mathrm{o}}\right)\end{array}$ & $8.5 \mathrm{~mm}$ & - & 11.5 & $8.5 \mathrm{~mm}$ \\
\hline Length (L) & $273 \mathrm{~mm}$ & $\begin{array}{c}1.6,1.75 \\
, 1.9 \mathrm{~m}\end{array}$ & 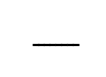 & $250 \mathrm{~mm}$ \\
\hline Width (W) & $268 \mathrm{~mm}$ & - & - & $238 \mathrm{~mm}$ \\
\hline Depth $(\mathrm{H})$ & $118 \mathrm{~mm}$ & - & - & $74 \mathrm{~mm}$ \\
\hline Fin height (y) & $4.2 \mathrm{~mm}$ & - & - & $4.2 \mathrm{~mm}$ \\
\hline $\begin{array}{l}\text { The distance } \\
\text { between two } \\
\text { fines }(\mathrm{z})\end{array}$ & $3.5 \mathrm{~mm}$ & - & - & $3.5 \mathrm{~mm}$ \\
\hline
\end{tabular}
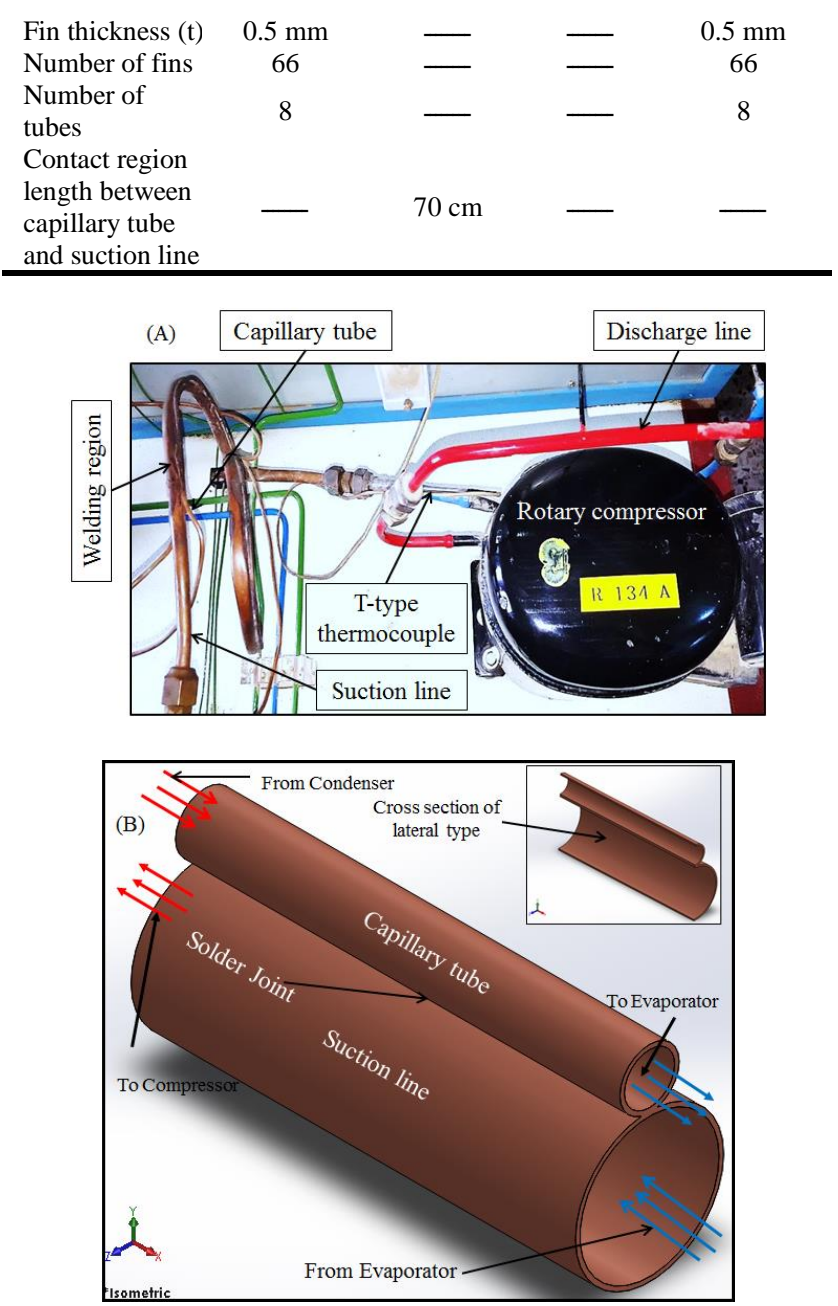

Figure 2. Lateral capillary tube with suction line; A). Photograph of heat exchanger (lateral suction line) with rotary compressor, B). Isometric drawing of lateral capillary with flow direction

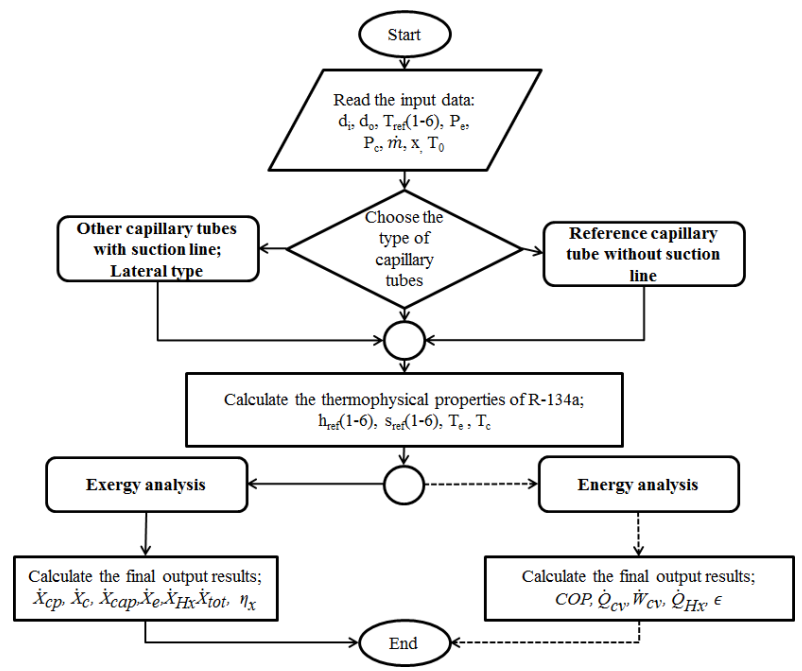

Figure 3. Flowchart diagram of the experimental energy and exergy analysis during the refrigeration process

\section{Energy and Exergy Analyses}

The refrigeration rig with the lateral suction line is illustrated in Figure 4 (A) and (B) that includes subcooling and superheating regions. 

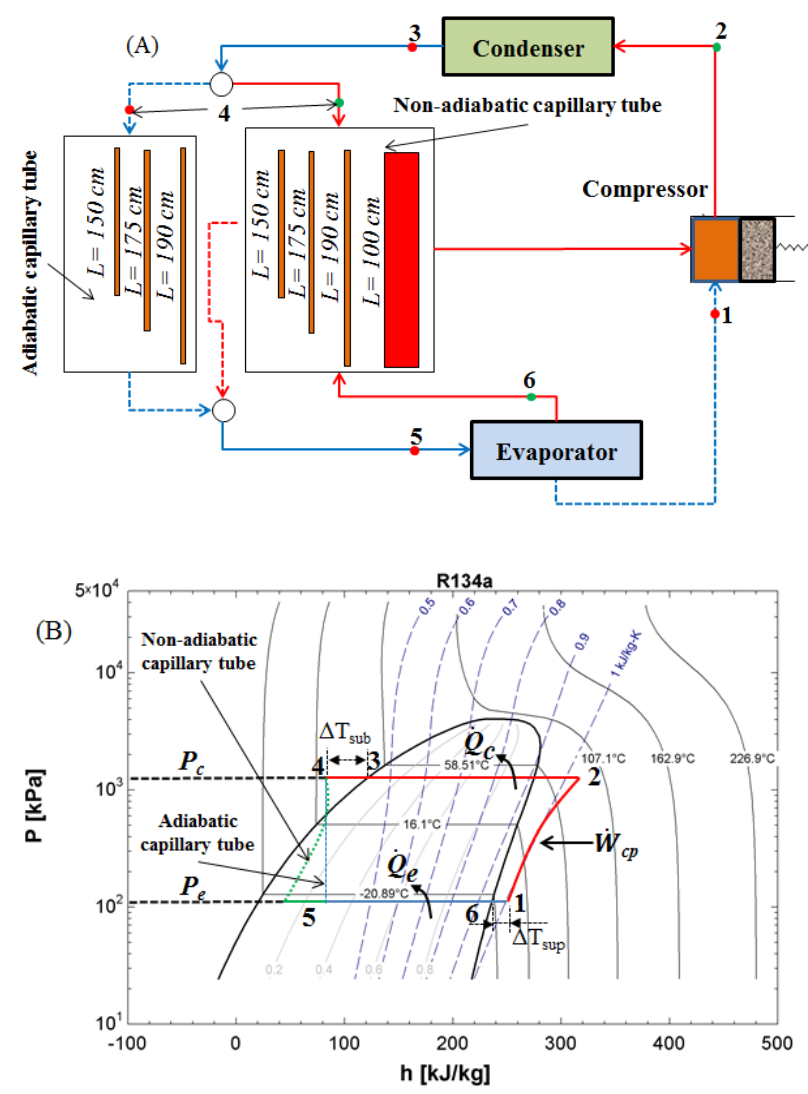

Figure 4. The block diagram (A) and p-h diagram (B) with adiabatic and non-adiabatic capillary tube of VCRS

The first law of thermodynamics is used to calculate the cycle performance as a coefficient of performance (COP) as given by Eq. (1) [1]:

$C O P=\frac{\dot{Q}_{e}}{\dot{W}_{c p}}=\frac{h_{1}-h_{5}}{h_{2}-h_{1}}$

The heat transfer rate and work for each VCRS component are determined by following the conservation of energy equation Eq. (2). The assumptions of all calculations are achieved at steady state condition and neglecting the kinetic and potential energies [32]

$\dot{Q}_{c v}-\dot{W}_{c v}=\sum_{o}(\dot{m} \cdot h)_{o}-\sum_{i}(\dot{m} \cdot h)_{i}$

In addition, a non-adiabatic capillary tube is a heat exchanger that can transfer energy from the hot fluid in the condenser to the cold vapor in the evaporator. The heat transfer process depends on the size and capillary suction line types such as (lateral, coil and concentric). The effectiveness and heat transfer rate of the heat exchanger (non-adiabatic capillary tube) are defined in Eqs. (3) and (4) [33]

$\dot{Q}_{H x}=\dot{m}\left(h_{4}-h_{5}\right)=\dot{m}\left(h_{1}-h_{6}\right)$

$\epsilon=\frac{T_{1}-T_{6}}{T_{4}-T_{6}}$

The second law of thermodynamics refers to the concept of exergy and energy quality. Then, the definition of exergetic efficiency in the VCRS is the ratio of the minimum exergy demanded to the real exergy consumed during cooling process, which is calculated by [34] :
$\eta_{X}=1-\frac{\dot{\boldsymbol{X}}_{t o t}}{\left|\dot{\boldsymbol{W}}_{c p}\right|}=\frac{\dot{Q}_{e}}{\left|\dot{\boldsymbol{W}}_{c p}\right|}\left(1-\frac{T_{0}}{T_{e}}\right)$

Where, the total exergy rate is calculated by:

$\dot{X}_{t o t}=\dot{X}_{e}+\dot{X}_{c}+\dot{X}_{c p}+\dot{X}_{c a p}+\dot{X}_{H x}$

Then, the exergy destroyed for each component of the refrigeration system can be determined as:

(a) Evaporator:

$\dot{X}_{e}=\dot{m} \varphi_{5}-\dot{m} \varphi_{1}+\dot{Q}\left(1-\frac{T_{0}}{T_{e}}\right)=\dot{m}\left[\left(h_{5}-T_{0} \cdot s_{5}\right)-\left(h_{1}-T_{0} \cdot s_{l}\right)\right]+\dot{Q}(1-$

$\left.\frac{T_{0}}{T_{e}}\right)$

(b) Condenser:

$\dot{X}_{c}=\dot{m} \cdot \varphi_{2}-\dot{m} \cdot \varphi_{4}=\dot{m}\left[\left(h_{2}-T_{0} \cdot s_{2}\right)-\left(h_{4}-T_{0} \cdot s_{4}\right)\right]$

(c) Compressor:

$\dot{X}_{c p}=\dot{m} \varphi_{1}-\dot{m} \varphi_{2}+\left|\dot{W}_{c p}\right|=\dot{m}\left[\left(h_{1}-T_{0} s_{1}\right)-\left(h_{2}-T_{0} s_{2}\right)\right]+\left|\dot{W}_{c p}\right|$

(d) Capillary tube:

$\dot{\boldsymbol{X}}_{\text {cap }}=\dot{m} \cdot \varphi_{4}-\dot{m} \cdot \varphi_{5}=\dot{m}\left[\left(h_{4}-T_{0} s_{4}\right)-\left(h_{5}-T_{0} s_{5}\right)\right]=\dot{m} T_{0}\left(s_{5}-s_{4}\right)$

(e) Heat exchanger (capillary tube-suction line "Cl-Slhx"):

$\dot{X}_{H x}=\dot{m} \cdot \varphi_{4}-\dot{m} \cdot \varphi_{5}+\dot{m} \cdot \varphi_{6}-\dot{m} \cdot \varphi_{1}=\dot{m} T_{0}\left[\left(s_{4}\right)-\left(s_{5}\right)+\left[\left(s_{1}\right)-\left(s_{6}\right)\right]\right]$

\section{Results and Discussion}

An experimental study was carried out to show the effect of adding a heat exchanger (suction line - capillary tube) on the comprehensive performance, as the coefficient of performance and exergy efficiency, in a compression refrigeration system with different capillary tube lengths and air velocities through the condenser. The experiments of the refrigeration system were tested within the range of volumetric flow rates from $0.175 \mathrm{~L} / \mathrm{min}$ to $0.3 \mathrm{~L} / \mathrm{min}$ by using the refrigerant R134a.

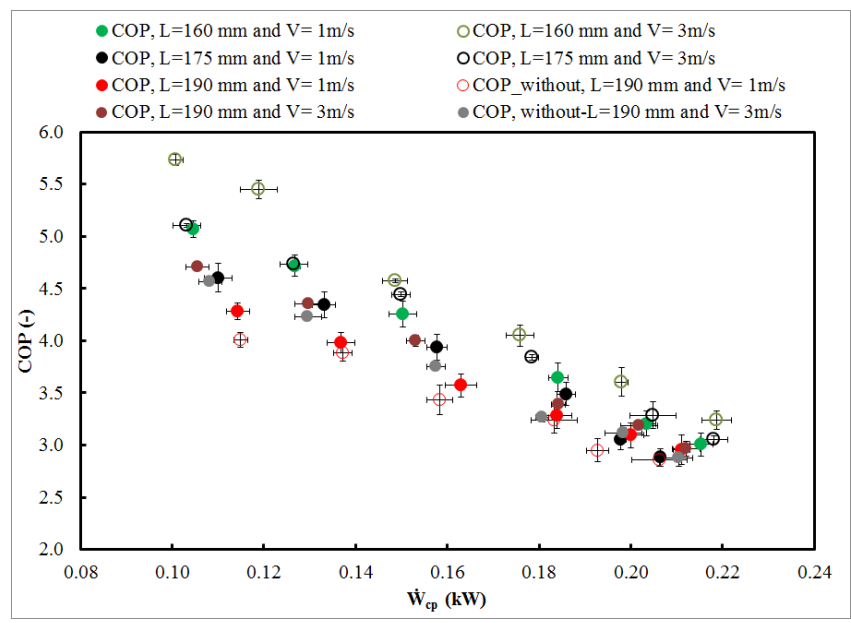

Figure 5. The effect of capillary tube length and air velocity on the coefficient of performance with variable compression power. 


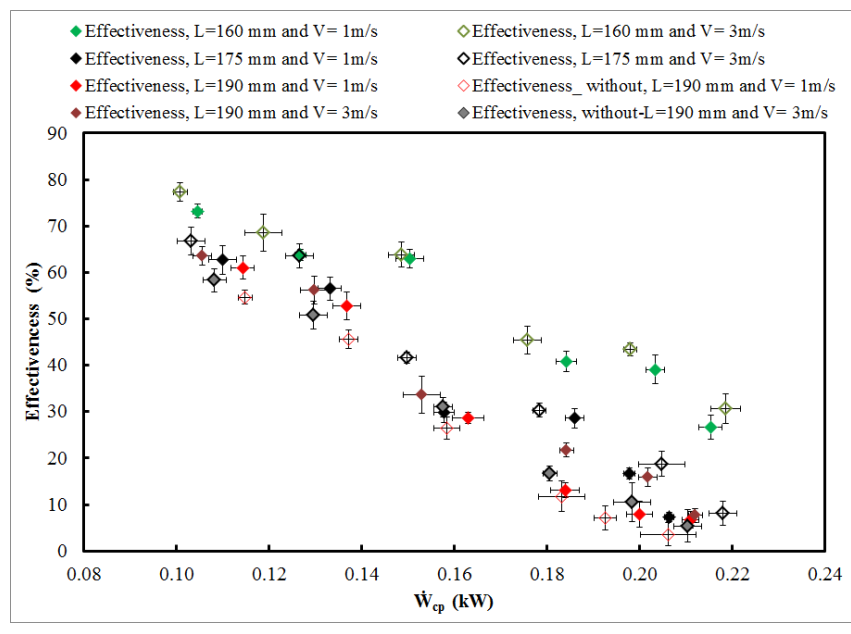

Figure 6. The heat exchanger effectiveness versus the compression power at different lengths for the capillary tubes and air velocity.

Figure 5) and (Figure 6) show the effect of compression power on the system performance and heat exchanger effectiveness. The coefficient of performance for the compression refrigeration system and the effectiveness of the heat exchanger decreases with the increase of the compression power. This is due to increasing the pressure drop and delaying the flashing point inside the capillary tube as the capillary tube length increment [35], which leads to a rise in the consumed capacity of the compressor. In addition, the experimental results illustrated a decrease in the coefficient of performance as the length of the capillary tube increases due to decrease each of the refrigerant velocity inside the capillary tubes and cooling capacity that leads to the increase of the friction coefficient. Heat exchanger (suction line - capillary tube) achieved a good enhancement in COP and the effectiveness compared with the reference capillary tube (without suction line) due to the increase in the subcooling zone. Finally, the heat transfer rate in the condenser elevated by increasing the air-speed from $1 \mathrm{~m} / \mathrm{s}$ to $3 \mathrm{~m} / \mathrm{s}$ that leads to increment in the refrigeration system performance, as COP and effectiveness. Therefore, the COP results showed maximum increase by $17.47 \%$ at $190 \mathrm{~cm}$ length of the capillary tube and $18.9 \mathrm{Kg} / \mathrm{hr}$ mass flow rate of the refrigerant. On the other hand, it is obvious that the COP increases with the increase in the effectiveness of the heat exchanger (capillary tube- suction line) for all cases.

The effect of the refrigerant volume flow rate on the exergy efficiency and subcooling temperature is shown in Figure 7 andFigure 8 ). The results reveal that the subcooling temperature and exergy efficiency decrease as higher volumetric flow rates are provided for all capillary tubes. This is due to a delay in the intersection point and the beginning of vaporization inside the capillary tube [35] that leads to a decrease in the subcooling temperature with the increases in superheating temperature. In addition, the impact of lengthening the capillary tube from $160 \mathrm{~mm}$ to 190 $\mathrm{mm}$ leads to reducing exergy efficiency and subcooling temperature for all cases. This can be attributed to the higher compression power of the compressor and exergy loss for all components in the refrigeration system with lower the refrigerant flow rates. Consequently, it can be concluded that exergy efficiency rises with the increment in the subcooling temperature and air velocity for all cases. Finally, the current energy and exergy analysis results are verified with another study by Fatouha and Abou-Ziyana [36] using a refrigerant type R134a and suction line heat exchanger. The results of COP and exergy efficiency gave the same behavior of [36], i.e. decreased with increasing the capillary tube length.

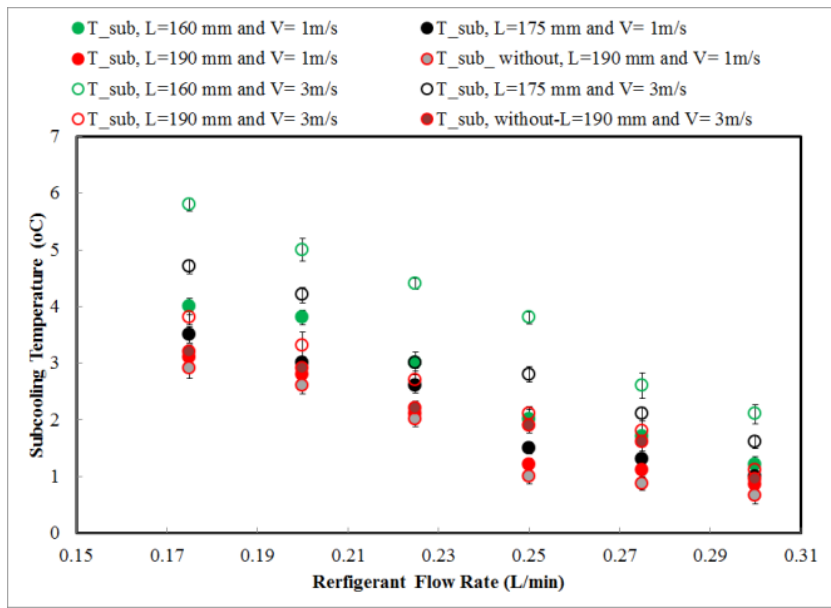

Figure 7. The effect of length capillary tube and air fan speed of condenser on subcooling tempreature with variable refrigerant flow rate.

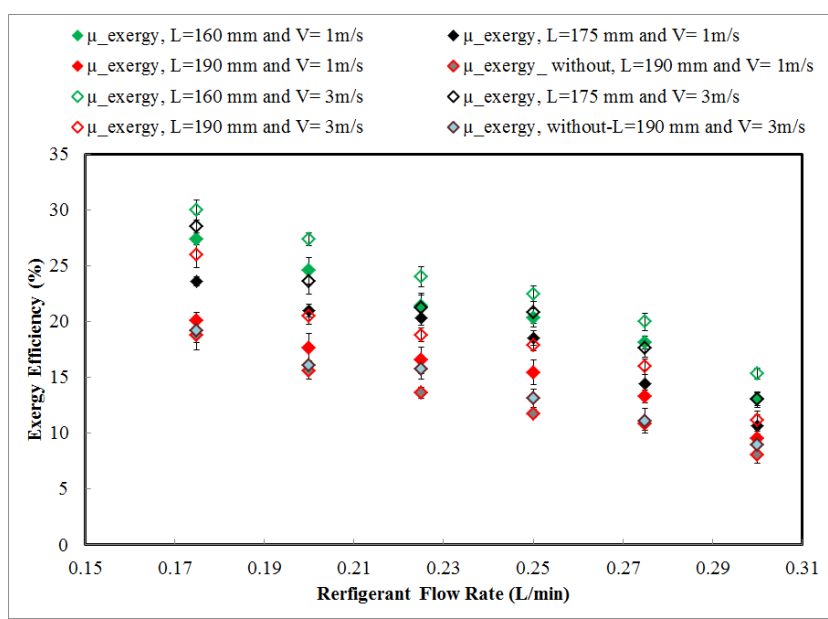

Figure 8. The effect of refrigerant flow rates on the exergy efficiency at different capillary tube lengths and air velocity.

\section{Conclusion}

In this research, an experimental study was presented the lateral suction line that effects on the refrigeration system performance by utilizing different lengths of capillary tubes $160 \mathrm{~cm}$ to $190 \mathrm{~cm}$. Besides, all the experimental tests were achieved with a refrigerant flow rate range from $0.175 \mathrm{~L} / \mathrm{min}$ to $0.3 \mathrm{~L} / \mathrm{min}$. Then, the summary of results can be abbreviated as:

1 The system performance decreases by increasing the mass flow rate of the refrigerant due to an increase in the power consumption of the compressor, which leads to elevating the required amount of refrigerant.

2 Increasing the length of the capillary tube leads to a decrease the performance coefficient. The highest value obtained for the performance coefficient was for the capillary tube length $(160 \mathrm{~cm})$, and the highest percentage in the performance coefficient compared to the length of 
3 the capillary tube $(190 \mathrm{~cm})$ is $(17.96 \%)$ at air speed $(3 \mathrm{~m} / \mathrm{s})$ and refrigerant mass flow rate of (17.3 Kg/hr).

4 By increasing the air speed from $1 \mathrm{~m} / \mathrm{s}$ to $3 \mathrm{~m} / \mathrm{s}$, the coefficient of performance increases by $17.47 \%$ at the capillary tube length of $190 \mathrm{~cm}$ and the refrigerant mass flow rate of $18.9 \mathrm{Kg} / \mathrm{hr}$.

5 The heat exchanger (capillary tube-suction line) offered a good enhancement in refrigeration system performance COP and exergy efficiency compared to the reference refrigeration system at capillary tube length of $190 \mathrm{~cm}$.

6 The scientific reasons and behaviors trends of outcome results were validated by comparing them with other publications' [35] and [36].

\section{Acknowledgements}

The authors would like to thank the Tikrit University for supporting us to use the laboratory facilities in the mechanical engineering department.

\section{Nomenclature}

\begin{tabular}{|c|c|c|c|}
\hline$d$ & Capillary tube diameter, $(\mathrm{m})$ & $\varphi$ & $\begin{array}{l}\text { Flow exergy, } \\
\left(\mathrm{kJkg}^{-1}\right)\end{array}$ \\
\hline$h$ & Enthalpy, $\left(\mathrm{kJkg}^{-1}\right)$ & $\Delta T$ & $\begin{array}{l}\text { Temperature } \\
\text { difference. }\left({ }^{\circ} \mathrm{C}\right)\end{array}$ \\
\hline$L$ & Capillary tube length, (m) & \multicolumn{2}{|c|}{ Subscripts } \\
\hline$\dot{\mathrm{m}}$ & $\begin{array}{l}\text { Refrigerant mass flow rate, } \\
\left(\mathrm{kghr}^{-1}\right)\end{array}$ & 0 & Referance \\
\hline$P$ & Pressure, (bar) & $c$ & Condenser \\
\hline$\dot{Q}$ & Heat rate, $(\mathrm{kW})$ & cap & Capillary \\
\hline$\dot{Q}_{c}$ & Condenser heat rate, $(\mathrm{W})$ & $c p$ & Compressor \\
\hline$T$ & Temperature, $\left({ }^{\circ} \mathrm{C}\right)$ & $c v$ & Control volume \\
\hline & Specific entropy, $\left(\mathrm{Jkg}^{-1} \mathrm{~K}^{-1}\right)$ & $e$ & Evaporator \\
\hline$V$ & Velocity, $\left(\mathrm{ms}^{-1}\right)$ & $H x$ & Heat exchanger \\
\hline$\dot{V}$ & Volume flow rate, $\left(\mathrm{m}^{3} \mathrm{hr}^{-1}\right)$ & $i$ & Inlet \\
\hline$W$ & Work rate, $\left(\mathrm{kJkg}^{-1}\right)$ & $o$ & Outlet \\
\hline$\dot{W}$ & Power, $(\mathrm{kW})$ & $s u b$ & Subcooling \\
\hline$x$ & Quality, (-), & sup & superheating \\
\hline & Exergy rate, $(\mathrm{W})$ & tot & Total \\
\hline \multicolumn{2}{|c|}{ Dimensionless groups } & & Exergy \\
\hline $\mathrm{COH}$ & Coefficient of performance & \multicolumn{2}{|c|}{ Abbreviations } \\
\hline \multicolumn{2}{|c|}{ Greek symbols } & $\mathrm{Cl}$ & $\begin{array}{l}\text { Capillary tube } \\
\text { line }\end{array}$ \\
\hline$\eta_{X}$ & Exergy efficiency, (\%) & & $\begin{array}{l}\text { Suction line } \\
\text { Vapor }\end{array}$ \\
\hline$\varepsilon$ & Effectiveness, (-) & $V C R S$ & $\begin{array}{l}\text { Compression } \\
\text { Refrigeration } \\
\text { System }\end{array}$ \\
\hline
\end{tabular}

\section{References}

[1] T. H. Kuehn, J. W. Ramsey, J. L. Threlkeld, Thermal environmental engineering, $3^{\text {rd }}$ Ed., Prentic Hall, 1998.

[2] W. F. Stoeker, refrigeration and air condition, $2^{\text {nd }}$ Ed., Mc Graw-Hill, 1982.

[3] A. D. Althouse, C. H. Turnquist, A. F. Bracciano, Modern refrigeration and air conditioning, $18^{\text {th }} E d$. hardback, Goodheart- Willcox, 2003.

[4] K. A. Al-judi, principles of air conditioning and refrigeration, College of Engineering, Al-Basrah University, 1986.

[5] S.J. Kuehl , V.W. Goldschmidt, "steady flows of R22 through capillary tubes: test data," ASHRAE Trans., 96, 1, 719-728, 1990.

[6] O. García-Valladares, "Numerical simulation of nonadiabatic capillary tubes considering metastable region. Part II: Experimental validation," Int. J. Refrig., 30, 654-663, 2007.

[7] S. Park, K. Son, J. Jeong, L. Kim, "Simulation of the effects of a non-adiabatic capillary tube on refrigeration cycle," International Refrigeration and Air Conditioning Conference at Purdue: pp. 1-8, 2008.

[8] T. K. Salim, S. S. Farhan, S. M. Khalaf, "an experimental study to show the effect of difference in capillary tube length on compression refrigeration system performance by using the refrigerant R134a," Tikrit J. Eng. Sci., 15, 14-28, 2008.

[9] M. K. Khan, R. Kumar, P. K. Sahoo, "Experimental investigation on diabatic flow of R-134a through spiral capillary tube," Int. J. Refrig., 32, 261-271, 2009.

[10] C. J.L. Hermes, C. Melo, F. T. Knabben, “Algebraic solution of capillary tube flows. Part II: Capillary tube suction line heat exchangers," Appl. Therm. Eng., 30, 770-775, 2010.

[11] L. S. Kim, K. Son, D. Sarker, J. H. Jeong, S. H. Lee, "An assessment of models for predicting refrigerant characteristics in adiabatic and non-adiabatic capillary tubes," Heat mass Transf., 47, 163-180, 2011.

[12] S. Y. Hussain, "Experimental investigation of condensation of refrigerant R134a and R12 in air cooled horizontal condenser," J. Eng. Dev., 15, 155-172, 2011.

[13] M. M. Shah, "A general correlation for heat transfer during film condensation inside pipes," Int. J. Heat Mass Transf., 22, 547-556, 1979.

[14] J. U. Ahamed, R. Saidur, H. H. Masjuki, “A review on exergy analysis of vapor compression refrigeration system," Renew. Sustain. Energy Rev., 15, 3, 1593-1600, 2011.

[15] D. Sarker , J. H. Jeong, "Development of empirical correlations for non-adiabatic capillary tube based on mechanistic model," Int. J. Refrig., 35, 974-983, 2012.

6] K. C. Mendonca, C. Melo, R. T. S. Ferreira, R. H. Pereira, "Experimental study on lateral capillary tube-suction line heat exchangers," International Refrigeration and Air Conditioning Conference at Purdue: pp. 437-442, 1998.

[17] D. A. Wolf , M. B. Pate, "Capillary tube-suction line heat exchanger performance with alternative refrigerants," ASHRAE Res. Proj. RP-762, Final Rep., 2002.

[18] J. H. Jeong, S.-G. Park, D. Sarker, K. S. Chang, "Numerical simulation of the effects of a suction line heat exchanger on vapor compression refrigeration cycle performance," J. Mech. Sci. Technol., 26, 1213-1226, 2012.

[19] N. A. Ansari, B. Yadav, J. Kumar, "Theoretical exergy analysis of HFO-1234yf and HFO-1234ze as an alternative replacement of HFC-134a in simple vapour compression refrigeration system," Int. J. Sci. Eng. Res., 4, 137-144, 2013. 
[20] M. Chandrasekharan, "Exergy analysis of vapor compression refrigeration system using R12 and R134a as refrigerants," Int. J. Students' Res. Technol. Manag., 2, 134-139, 2014.

[21] J. Deshmukh, D. K. Mudaiya, "Mathematical modelling for refrigeration flow in diabatic capillary tube," Int. J. Latest Trends Eng. Technol., 6, 196-203, 2016.

[22] N. N. Raja , A. D. Khanderao, "Experimental Investigation on the Effect of Capillary Tube Geometry on the Performance of Vapor Compression Refrigeration System," Asian J. Eng. Appl. Technol., 5, 29-35, 2016.

[23] M. dos Santos Guzella, L. Cabezas-Gómez, L. G. M. Guimarães, C. B. Tibiriçá, "A modified approach for numerical simulation of capillary tube-suction line heat exchangers," Appl. Therm. Eng., 102, 283-292, 2016.

[24] C. L. Zhang, G. L. Ding, "Modified general equation for the design of capillary tubes," J. Fluids Eng., 123, 914-919, 2001.

[25] C. Melo, J. M. Zangari, R. T. S. Ferreira, R. H. Pereira, "Experimental studies on non-adiabatic flow of HFC-134a through capillary tubes," International Refrigeration and Air Conditioning Conference at Purdue: pp. 305-312, 2000.

[26] C. Melo, L. A. T. Vieira, R. H. Pereira, "Nonadiabatic capillary tube flow with isobutane," Appl. Therm. Eng., 22, 1661-1672, 2002.

[27] A. A. Mohammed , A. A. Nasser, "Experimental And Mathematical Evaluation Of The Refrigeration System Performance With Different Ambient Temperature," J. Eng. Sustain. Dev., 21, 6, 1-19, 2017.

[28] L. A. A. Mahdi, W. S. Mohammad, S. A. Mahmood, "Exergy Analysis of a Domestic Refrigerator," J. Eng., 24, 1-20, 2018.
[29] S. K. Dubba ,R. Kumar, "Experimental investigation on flow of R-600a inside a diabatic helically coiled capillary tube: Concentric configuration," Int. J. Refrig., 86, 186-195, 2018.

[30] C. Melo, R. T. S. Ferreira, C. B. Neto, J. M. Goncalves, M. M. Mezavila, "An experimental analysis of adiabatic capillary tubes," Appl. Therm. Eng., 19, 669-684, 1999.

[31] I. M. A. Aljubury , M. A. Mohammed, "Heat Transfer Analysis of Conventional Round Tube and Microchannel Condensers in Automotive Air Conditioning System," J. Eng., 25, 38-56, 2019.

[32] C. Stanciu, A. Gheorghian, D. Stanciu, A. Dobrovicescu, "Exergy analysis and refrigerant effect on The operation and performance limits of a One stage vapor compression Refrigeration system," Termotehnica, 1, 36-42, 2011.

[33] S. A. Klein, D. T. Reindl, K. Brownell, "Refrigeration system performance using liquidsuction heat exchangers," Int. J. Refrig., 23, 588596, 2000

[34] M. Yilmaz, O. N. Sara, and S. Karsli, "Performance evaluation criteria for heat exchangers based on second law analysis," Exergy, an Int. J., 1, 278294, 2001.

[35] Ammar A. F. (2016). Experimental and Numerical Study for Refrigerant Flow through Capillary Tube within Metastable Region, (Master dissertation), University of Babylon.

[36] M. Fatouh , H. Abou-Ziyan, "Energy and exergy analysis of a household refrigerator using a ternary hydrocarbon mixture in tropical environmentEffects of refrigerant charge and capillary length," Appl. Therm. Eng., 145, 14-26, 2018. 